\title{
The Mathematical Model Refinement of the Continuous Digging Machine and Its Research
}

\author{
Juraj Gerlici'1, Svyatoslav Kravets², Mykhailo Honchar ${ }^{2}$, Andrii Koval², Anatolii Korpach², Tomas Lack ${ }^{1}$, Kateryna \\ Kravchenko ${ }^{1}$ \\ ${ }^{1}$ Faculty of Mechanical Engineering, University of Zilina. Univerzitná 8215/1, 01026 Zilina. Slovak Republic. \\ E-mail: juraj.gerlici@fstroj.uniza.sk, tomas.lack@fstroj.uniza.sk, kkatherina@ukr.net \\ ${ }^{2}$ Faculty of Automotive and Mechanical Engineering, National Transport University. M. Omelianovicha-Pavlenka, \\ 1, 01010 Kiev. Ukraine. E-mail: s.v.kravets@nuwm.edu.ua, gmo48@ukr.net, kandr@i.ua, akorpach@ukr.net
}

The article presents the results of theoretical research on creating the mobile continuous earthmoving machinery. The aim of the article is to develop and evaluate the effectiveness of technical decisions when creating and modernizing trencher chain and bar actuators. The peculiarity of the performed research is a complex way to solve the problems of ensuring the efficient operation of the earthmoving machinery. It involves a combination of two subsystems: "soil - operating equipment" and "basic chassis - bearing capacity of soil surface". The mechanisms of changing the power parameters of the machinery load are established. The input parameters for a system describing the operation of a special earthmoving machinery are soil physical and mechanical characteristics and the dimensions of the earth excavation, the installed power of the basic chassis engine, the type and characteristics of transmissions of the machinery operating equipment and chassis propulsion, geometric parameters of single cutters, the speed of cutting the soil and moving the machinery. The mathematical model of the system as a whole makes it possible to determine the rational design, kinematic and energy characteristics of the machinery and its operating equipment. It minimizes the energy intensity of soil development.

Keywords: Mobile Continuous Earthmoving Machinery, Trencher, Speed Of Cutting The Soil, Kinematic Characteristics Energy Characteristics.

\section{Introduction}

Trenchers are specific machinery that simultaneously cut the soil, remove it from the trench and lay it outside the area of the constructed trench in a given place. A vehicle as a mechanical system is exposed to loading $[1,2,3]$. The creation of the earthmoving machines raises the issues about the reducing of the labor and energy consumption that must be expended on the digging, i.e. the creation of such an executive device which would improve the performance of the machine, increase the efficiency of interaction with the soil and reduce the cost of the performed work $[3,4$, 5].

It is advisable, objective and generally accepted to evaluate the perfection of actuators and excavators for longitudinal digging in terms of energy consumption used for the development of $1 \mathrm{~m}^{3}$ of soil.

The energy consumption indicator largely reflects the overall perfection and efficiency of the machinery. Certainly, the actuator of the machinery should fully meet its technological purpose, have the necessary durability, reliability and endurance in operation. A higher criterion should be used as a general criterion for the technical and economic efficiency of the excavators. It involves the specific reduced costs - the full cost of developing a unit of soil volume taking into account operating costs, additional capital investments and their payback period.

\section{Review of the literature}

In paper [6], the movements of the analytical models of complete underwater tracked vehicle and cutterbar tool systems on a surface as well as their movements up and down a slope in the up-cutting modeoperation are fully studied and analyzed. Analyses on the systemicparameters and their sensitivity are conducted to observe the variations of the operational and geometricparameters, as well as the cutter-tool and material-condition effects on the force, moment, and power components.

Professor A.N. Zelenin [7] investigated the problem of the physical nature of digging, cutting forces depending on the soil conditions, the cross sectional area of the chip, the width and depth of the cut, and the cutting angle. It was found that the number of strokes of the dynamic density meter is directly proportional to the cutting force for any executive device, and it may be a criterion for the soil strength evaluation

When creating continuous earthmoving ma- 
chinery, first of all, it is necessary to consider and optimize the technological combination of the processes of cutting the soil, moving the developed soil from the face to the unloading zone and unloading the soil development actuator from the soil. To solve this problem in terms of energy intensity minimization when destructing and transporting the soil from the face, a specified mathematical model of the continuous earthmoving machinery has been created. It is based on the condition that the soil is developed by the actuator cutters at subcritical cutting depths [8 - 12]. This enables to determine the rational design and kinematic parameters of the special earthmoving machinery and its actuators. The machinery is considered to be a combination of two interacting subsystems: "soil - operating equipment" and "basic chassis - bearing capacity of soil surface".

3 The results of the research the chain and bar actuators of the continuous earthmoving machinery
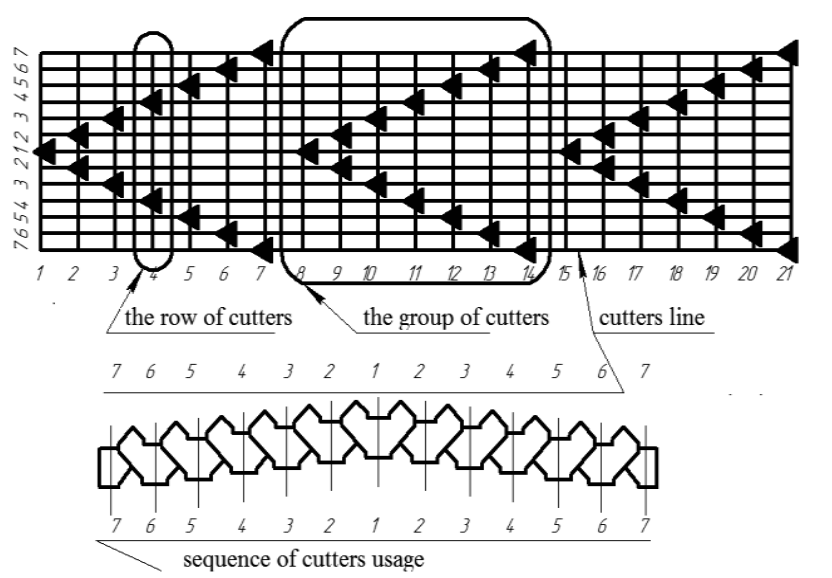

a)

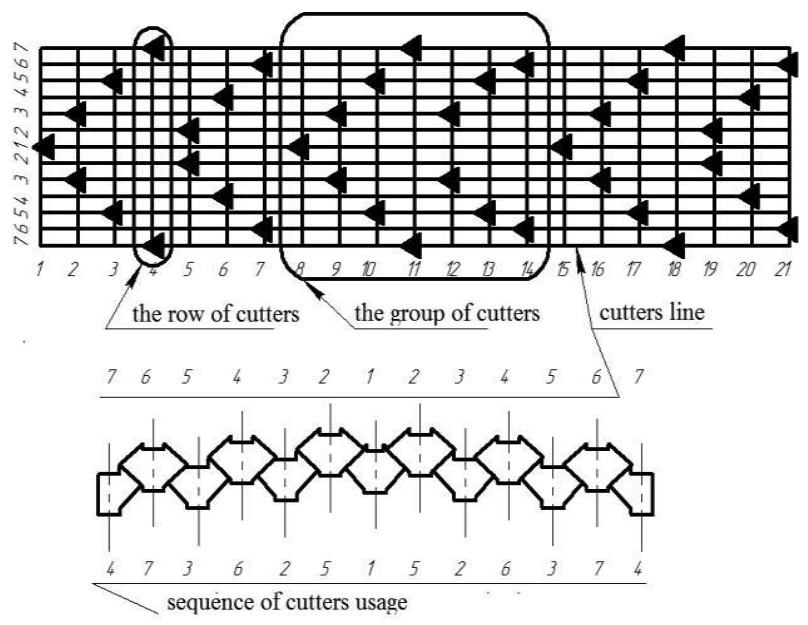

b)

Fig. 1 Cutter layout: (a) Stepped layout of cutters and soil destruction grid; (b) Symmetrical stepped and staggered layout of cutters and soil destruction grid
The subsystem "soil - operating equipment" is characterized by kinematic and geometric parameters of the actuator and the excavation under construction, physical and mechanical characteristics of the soil. It includes an analytical description of cutting the soil, moving it from the face to the place of unloading and unloading itself.

Cutting is viewed as the destruction of the soil area by separate cutters. Each cutter operates in the mode of blocked, semi-blocked, or free cutting at subcritical depths. The cutters are placed on the bars of the actuator according to the stepped or stepped and staggered layout, Fig. 1.

The operation of the subsystem "basic chassis bearing capacity of soil surface" is determined by the parameters of the power plant of the machinery, transmission units, machinery propulsion and its traction and coupling properties. The mathematical model of the subsystem takes into account the conditions of ensuring a stable contact of the supporting part of the basic chassis running track of the earthmoving machinery when digging the soil on a curved section of the road. It is possible if the traction force Trt in this track on the horizontal surface satisfies the following condition:

$$
T_{r t}^{h}=\frac{R}{2} f+\frac{R_{\mathrm{s}}}{2} \mu_{1}+\frac{R_{2}}{2}+\mu \frac{R L}{4 B} \cdot K
$$

on the slope:

$$
T_{r t}=\frac{R}{2} f \cos \alpha+\frac{R_{S}}{2} \mu_{1}+\frac{R_{2}}{2}+\mu \frac{R L}{4 B} K+\frac{R}{2} \sin \alpha,
$$

where $R$ is an equivalent of the vertical forces affecting the chassis; $f, \mu, \mu_{1}$ are, respectively, the coefficients of the machinery movement resistance, rotation and external soil friction; $R_{s}$ is a vertical load on additional supporting skis, if there are any; $R_{2}$ is a horizontal component of soil digging forces; $K$ is a coefficient of track uneven load; $a$ is an angle of the surface slope.

In general, the input parameters for a system describing the operation of a special earthmoving machinery are soil physical and mechanical characteristics and the dimensions of the earth excavation, the installed power of the basic chassis engine, the type and characteristics of transmissions of the machinery operating equipment and chassis propulsion, geometric parameters of single cutters, the speed of cutting the soil and moving the machinery. The output parameters include a capacity used, machinery performance and specific energy intensity of soil development. The task can be reversed. It means that under known soil conditions and geometric parameters of the soil excavation and given the machinery performance, the characteristics of operating equipment, the type and characteristics of transmissions and the machinery propulsion the required chassis power, traction and coupling characteristics of the propulsion and minimum energy 
intensity of soil development are determined. The mathematical model of the system as a whole makes it possible to determine the rational design, kinematic and energy characteristics of the machinery and its operating equipment. It minimizes the energy intensity of soil development.

The algorithm, Fig. 2, and the calculation programme developed in the research enable to optimize the design and operating modes of special continuous earthmoving machinery actuators. They take into account physical and mechanical properties of soils, the adopted restrictions and the design of soil development cutters.

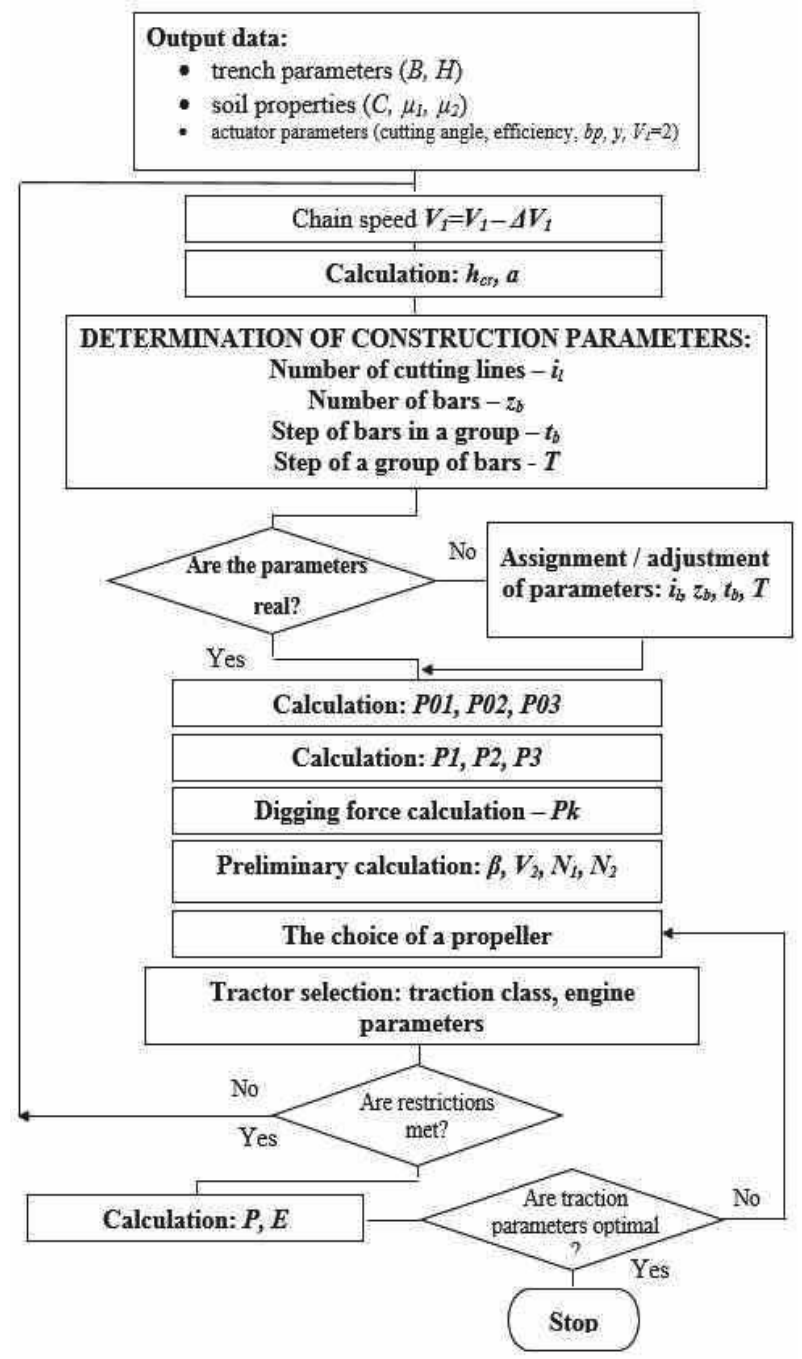

Fig. 2 A structural scheme of the algorithm for determining actuator parameters

The results of the research show that the chain and bar actuators of the continuous earthmoving machinery when digging the trenches of the sizes specified above in the soils of category II-IV, should use soil development cutters of width $\mathrm{b}=0.03 \mathrm{~m}$. They should be reinforced by wear-resistant plates VK-15 or VK-20, for example. The use of cutters of the specified structure, placed on the bars of the chain and bar actuator according to the stepped layout, enables to cut the soil at a critical depth of cutting. It means with the minimum energy intensity of soil destruction, Fig. 3.

With the change of the category of the soil development the energy intensity of its development is expected to change, namely from $0.078 \mathrm{kWh} / \mathrm{M}^{3}$ for category I to $0.482 \mathrm{kWh} / \mathrm{M}^{3}$ for category IV. It should be noted that in this case (when changing the category of the soil development) energy intensity of the development is minimum when using single cutters $\mathrm{b}=$ $0.03 \mathrm{~m}$.

When digging the soil, the cutting force ranges from $61 \%$ (Category I) to $93 \%$ (Category IV) of the total digging force by the chain and bar actuator. This confirms the correct orientation of the mathematical model to solve the problem of determining the ways of minimizing the soil cutting forces by chain and bar actuators of the continuous earthmoving machinery.

The research stated the influence of changing the shaving thickness cut off by cutters $b=0.03 \mathrm{~m}$ and force characteristics of digging the soil at subcritical depth on the change of machinery movement speed, Fig. 4.

The magnitude of the horizontal component of soil digging due to the traction force of the chassis does not exceed $25-30 \%$ of the maximum traction force of the chassis. It indicates the guaranteed stability of a contact of the machinery propulsion with the soil and the absence of objective preconditions for possible slipping of propellers, or the machinery cross hunting when it moves along a curvilinear trajectory of motion. The feed rate of the machinery actuator to the face when digging trenches with the condition of cutting the soil in a stable mode at a critical depth $\left(\mathrm{V}_{\mathrm{p}}\right.$ $=1.6 \mathrm{~m} / \mathrm{s}$ ) can reach $650-720 \mathrm{~m} / \mathrm{h}$. It corresponds the theoretical performance of the actuator in terms of endurance.

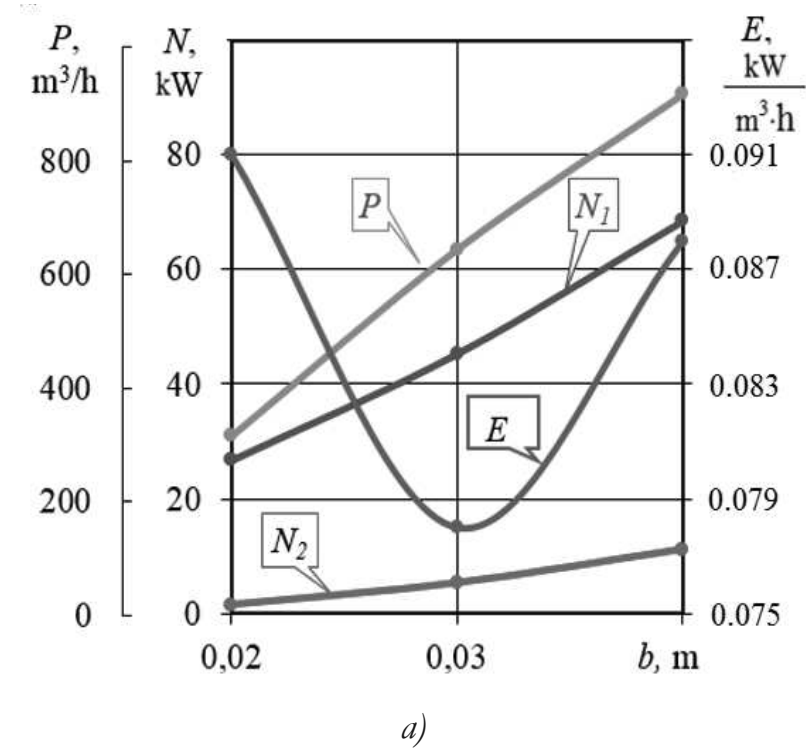




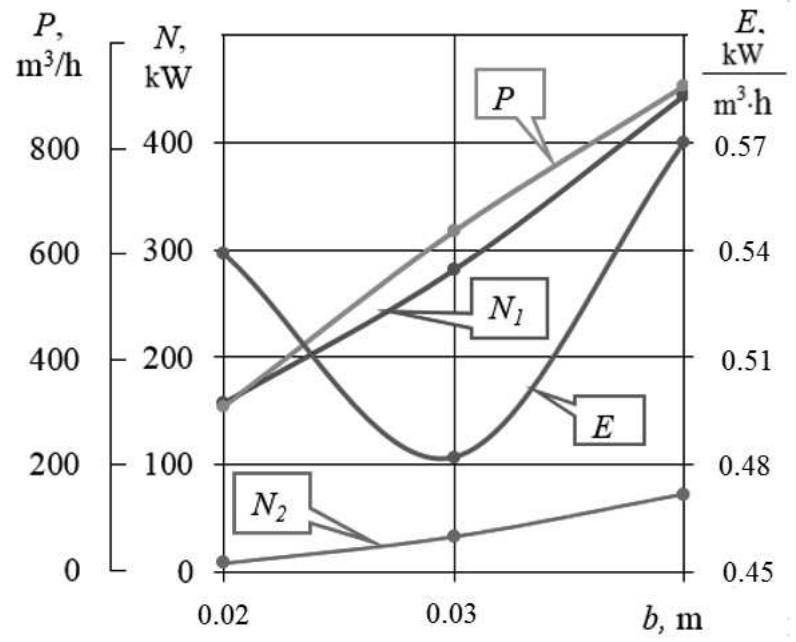

b)

Fig. 3 The influence of the width of the cutter on the characteristics of the digging process in different soils: $P$ is a performance; $N_{1}$ is a power at the actuator drive; $N_{2}$ is a feed power; $E$ is an energy intensity of soil development (a) - In the soils of category I; (b) - In the soils of category IV

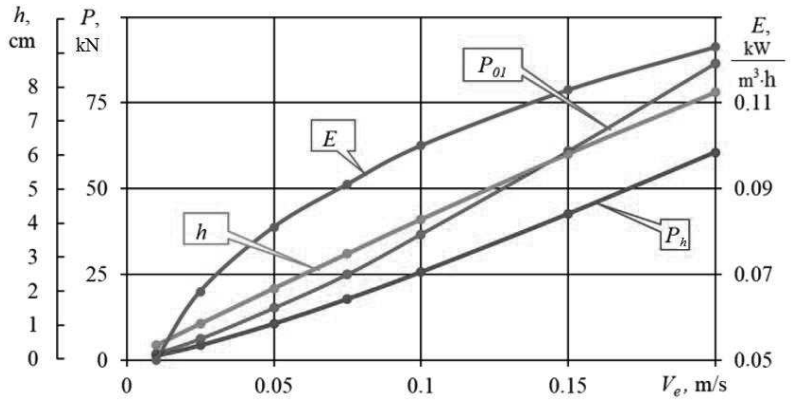

Fig. 4 Dependences of shaving thickness and parameters of actuator force loading on the change of machinery movement speed $V_{e}: H=3.3 \mathrm{M} ; B=0.6 \mathrm{M} ; C=16 ; V_{p}=1.6 \mathrm{~m} / \mathrm{s}$

The fact that there is a reverse transfer of the developed soil again in the trench is noted by all researchers of the continuous earthmoving machinery, for example $[9,13,14]$. The question is solely about the quantitative characteristics of the magnitude of the transfer. The greater the viscosity and stickiness of the soil developed the greater the magnitude of the transfer. The magnitude of the reverse transfer can reach $25-40 \%$ of the soil volume transported for unloading [15]. The productivity of the actuator in terms of endurance is reduced by the same amount. It is the inability of the actuator to lift and unload the developed soil that causes the soil development actuators to be jammed in the soil. It makes the machinery operation impossible. Special markings are made in the machinery registration certificates by the manufacturers.

One of the essential moments of effective unloading of the developed soil is to ensure its effective separation from the transporting surfaces of bars (scrapers) or buckets. Under conditions of gravitational unloading, the soil cutting speed should be $1.5-2.2 \mathrm{~m} / \mathrm{s}$ for chain bucket actuators, and $1.5-2.5 \mathrm{~m} / \mathrm{s}$ for scraper and bar actuators $[9,13,16]$.

In fact, the performance of the chain and bar and rotor actuators of the continuous earthmoving machinery is determined by their carrying capacity (endurance). The structural perfection is determined by the minimum of energy intensity of the soil development and the absence of residual soil sills at the bottom of excavations under construction. Effective unloading of the actuators must take place when working at each of the possible modes of digging the soil, both when changing the geometric position of the actuator at the face (when changing the depth of the excavation), and when changing the physical and mechanical characteristics of the developed soils.

To solve this problem, it is necessary to ensure that when digging the soil, a separation of the soil developed and transported from the face from the transportation surfaces of the actuator and the removal of this soil beyond the contours of the actuator and a profile of the excavation is guaranteed.

To estimate the effect of impulse intensification of unloading the chain and bar actuator with flexible transportation surfaces installed on it (Fig. 5), it is necessary to note the fact that the whole mass of the developed soil transported for unloading by a single flexible surface is an elementary volume focused at one point. It is affected by the force of the soil gravity, the coupling and the friction on the transportation surface. The inertia force applied to the mass of the elementary volume is determined by the "instantaneous" opening of this surface.

The research resulted in a dependence to determine the acceleration of the mass of the elementary soil volume. It causes the impulse of forces at the moment of separating the soil from the flexible surface:

$$
\mathrm{a}_{\mathrm{i} n}=-\sqrt{\left(\frac{d^{2}}{d t^{2}} X_{C}(t)\right)^{2}+\left(\frac{d^{2}}{d t^{2}} Y_{C}(t)\right)^{2}},
$$

where $a_{\text {in }}$ is an acceleration of the mass of the elementary soil volume; $\mathrm{XC}$ and $\mathrm{YC}$ are coordinates of point C.

With the average soil stickiness in Ukraine of $0.5 \cdot 10^{5} \mathrm{~Pa}$, the minimum acceleration of the center of the soil mass $C$ on a flexible surface $a_{\min } \cong 3.5 \mathrm{~m} / \mathrm{s}^{2}$ ensures a complete cleaning of the actuators from the transported soil, regardless of the design of the mechanism for providing the acceleration.

Analytical dependences obtained as a result of the research enabled to synthesize the design of transportation bars with a guaranteed complete unloading of sticky soils, Fig. 6. It also enabled to introduce the created design in the industrial production of earthmoving machinery.

Theoretical studies and their results, Fig. 7, show that if the traction chains of the unilateral bend $(\mathrm{r}=$ 
$0.15 \mathrm{~m}, \omega=6.67 \mathrm{rad} / \mathrm{s}$ ) are used in the chain and bar actuators when finishing the complete opening of the transportation surface, the acceleration of the center of mass of the elementary soil volume on a flexible surface $\mathrm{a}=16.4 \mathrm{~m} / \mathrm{s}^{2}$ is achieved. It is enough to ensure complete unloading of sticky soil from the chain and bar actuator of the earthmoving machinery.

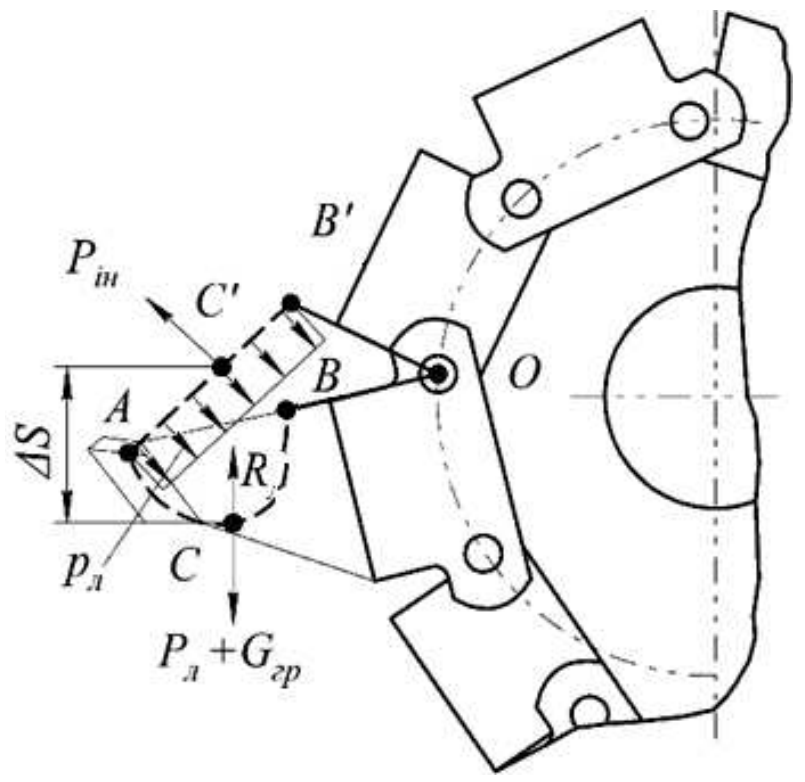

Fig. 5 Calculation scheme for determining the angle of "opening" the flexible surface of the bar

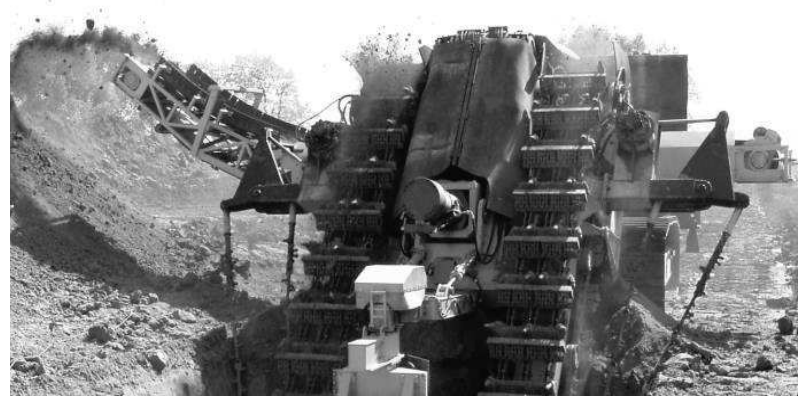

Fig. 6MVT-2M pipeline opening machinery with the actuator equipped with impulse soil unloading intensifier

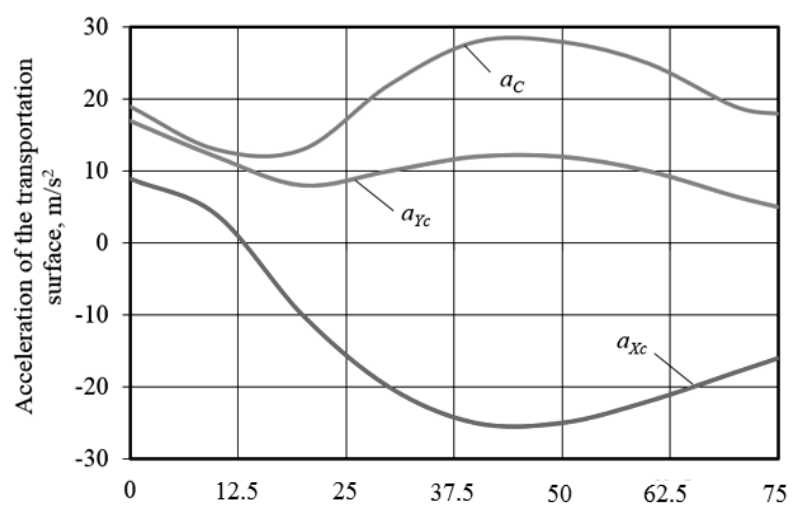

Fig. 7 Changing the acceleration of the transportation surface $a_{c}$ and its components $a_{X c}$ and $a_{Y_{c}}$ depending on the rotation angle of the chain link.

\section{Conclusions}

The refined mathematical model of continuous earthmoving machinery is based on the condition that the soil is developed by actuator cutters at subcritical cutting depths. It enables to determine the rational design and kinematic parameters of special earthmoving machinery in terms of energy intensity minimization. The machinery is considered to be a combination of two subsystems: "soil - operating equipment" and "basic chassis - bearing capacity of soil surface".

It has been established that the chain and bar actuators of the continuous earthmoving machinery should use soil development cutters of width $b=0.03$ $\mathrm{m}$. They should be reinforced by wear-resistant plates VK-15 or VK-20, for example, placed according to the stepped layout. The energy intensity of soil excavation of categories $\mathrm{I}-\mathrm{V}$ when constructing trenches and ditches varies within $0.078 \mathrm{kWh} / \mathrm{M}^{3}-0.482$ $\mathrm{kWh} / \mathrm{M}^{3}$. It has been proven that the feed rate of the machinery actuator to the face when digging the trench at a critical depth $(\mathrm{Vp}=1.6 \mathrm{~m} / \mathrm{s})$ can reach 650 $-720 \mathrm{~m} / \mathrm{h}$. This corresponds the theoretical performance of the actuator in terms of carrying capacity (endurance). It implies the provision that the actuator is completely unloaded from the transported soil and the reverse transfer of the developed soil again to the face is eliminated. Its volume can reach $25-40 \%$ of the developed soil.

\section{References}

[1] DIŽO, J., BLATNICKÝ, M. (2019). Investigation of ride properties of a three-wheeled electric vehicle in terms of driving safety. In: Transportation Research Procedia 40, pp. 663 - 670.

[2] BARAN, P., ŠASTNIAK, P., KUKUČA, P., BREZÁNI, M. (2018). Investigation of kinematic parameters of two nonconventional piston machines with wobble board, MATEC Web of Conferences 157, (14 March 2018, 02003, 22nd Slovak-Polish Scientific Conference on Machine Modelling and Simulations, MMS 2017; Sklene Teplice; Slovakia).

[3] TURUSBEKOV, K., M. TUSUPBEKOV, N. KHON, R. GABDYSALYK, S. TURUSBEKOV AND D. ZHAILAUBAEV. (2015). The Improvement of the Digging Process with the Sliding Surface Consideration. In: Biosciences Biotechnology Research Asia 12(3), pp. 2995 - 3008. Oriental Scientific Pub. Co.

[4] BLATNICKÁ, M., BLATNICKÝ, M., DIŽO, J., SÁGA, M. (2018). Comparison of analytical stress analysis and numerical calculation of mobile work machine part. In: Manufacturing Technology 18(2), pp. 190-193. 
[5] BLATNICKÝ, M., DIŽO, J., ŠTAUDEROVÁ, M. (2017). Strength analysis of a structure for attachment of a winch on SUV. In: Manufacturing Technology 17(2), pp. 147151.

[6] CHOI, M.T. VU, H.-S., NGUYEN, N.D., KIM, S.-K. (2019). Analytical design of an underwater construction robot on the slope with an up-cutting mode operation of a cutter bar. In: Applied Ocean Research 86, 289-309.

[7] ZELENIN, A.N., BALOVNEV, A.Y., KEROV, I.P. (1975). Machines for earthworks. In: Engineering, 423 p. Moscow.

[8] KRAVCHENKO, A., SAKNO, O., LUKICHOV, A. (2014). Trucks tires resource controlling by control of process of their wearing-out. In: Transport Problems 9(1), pp. 83 - 93/

[9] MUSIYKO, V.D. (2018). Theory and Creation of Innovative Continuous Earthmoving Macbines. Monograph, 282 p. Kyiv: Lyudmila Publishing House.

[10] VETROV, YU. A. (1971). Soil cutting by earthmoving machinery. In: Engineering, 360 p. Moscow.

[11] KRAVETS, S.V., CANT, O.V., GAPONOV, R.O., YANCHIK, T.O. (2019). Visiting date of the line and the road of the transport scraper in the lance-scraper trench excavator. In: Collection of scientific papers. Construction. Materials Science. Engineering. Intensification of work processes of construction and road machines. Series: Hoisting-andtransport, construction and road machines and equipment 107, pp. 66 - 74. State Higher Educational Institution "PGASA", Dnipro, Ukraine.

[12] USTINOV, A.V. (2006). Improving the scraper soil harvester in order to increase the productivity of the buckettless valuable trencher. Abstract Ph.D. thesis. 22 p. Tomsk state architect build university

[13] GARBUZOV, Z.E., ILGISONIS, V.K., MUTUSHEV G.A. et al. (1965). Earth-moving machinery of continuous operation. In: Engineering, 276 p. Moscow.

[14] KOTLOBAY A. YA. et al. (2013). Formation of modernization directions for earthmoving machinery. In: Science and technology 5, pp. $54-$ 60 Minsk.

[15] KOVAL, A.B. (2014). Determination of Conditions for Ensuring the Course Stability of Universal Earthmoving Machines. PhD thesis, 218 p. National University of Transport

[16] DOMBROWSKI, M.G. (1972). Bucket Excavators. Construction, theory and calculation. In: Engineering, 432 p. Moscow. 